Pacific Journal of Mathematics

COUNTEREXAMPLES TO CONJECTURES OF RYSER AND DE 


\title{
COUNTEREXAMPLES \\ TO CONJECTURES OF RYSER AND DE OLIVEIRA
}

\author{
ROY B. LEVOW
}

Let $U(n ; k)$ be the set of all $n \times n$ binary matrices with $k$ ones in each row and column. Considering the relation between the permanent and the determinant for matrices in $U(n ; k)$, Tinsley established the following result:

Theorem: Let $C \in U(7 ; 3)$ be the cyclic matrix defined by the differences $0,1,3(\bmod 7)$. Let $A \in U(n ; k)$ with $k \geqq 3$. Suppose that there are permutation matrices $P_{1}, P_{2}, \cdots, P_{k} \in$ $U(n ; 1)$ such that $A=P_{1}+P_{2}+\cdots+P_{k}$ and $P_{i} P_{j}=P_{j} P_{i}$ $(i, j=1, \cdots, k)$. Then $\operatorname{per} A=|\operatorname{det} A|$ if and only if $k=3$, $7 \mid n$, and the rows and columns of $A$ can be permuted in such a way that the resulting matrix is the direct sum of $C$ taken $n / 7$ times. Ryser posed

Conjecture I. Tinsley's Theorem remains valid when the condition $P_{i} P_{j}=P_{j} P_{i}(i, j=1, \cdots, k)$ is dropped.

Discovery of counterexamples to Conjecture I leads directly to counterexamples to the following conjecture of de Oliveira:

Conjecture II. Let $A$ be an $n \times n$ doubly stochastic irreducible matrix. If $n$ is even, then $f(z)=\operatorname{per}(z I-A)$ has no real roots; if $n$ is odd, then $f(z)=\operatorname{per}(z I-A)$ has one and only real root.

2. Preliminary results. Following the terminology of Harary $[6,7,8]$ we recall that with every digraph (with loops), $D$, we may associate a binary matrix, $A(D)$, the (point) adjacency matrix of $D$. Conversely, with every binary matrix, $A$, we may associate a digraph, $D(A)$, which has $A$ as its adjacency matrix. Given an $n \times n$ binary matrix, $A$, let $l_{+}\left(l_{-}\right)$denote the number of linear subgraphs of $D(A)$ which contain an even (respectively, odd) number of cycles of even length. Then as shown by Harary [6] $\operatorname{det} A=l_{+}-_{-} l_{-}$Similar reasoning yields the formula per $A=l_{+}+l_{-}$.

LEMMA 1. If $A$ is an $n \times n$ binary matrix with ones on the diagonal, then per $A=\operatorname{det} A$ if and only if every cycle of $D(A)$ is of odd length. Moreover, if $A$ is an arbitrary $n \times n$ binary matrix and $D(A)$ has only odd cycles, then per $A=\operatorname{det} A$.

Proof. This is an obvious consequence of the relation between the permanent, the determinant, and $D(A)$. 
An $n \times n$ matrix, $A$, is said to be indecomposable if there does not exist a permutation matrix, $P$, such that $P A P^{T}=A_{1} \oplus A_{2}$ for some matrices, $A_{1}$ and $A_{2} ; A$ is said to be fully indecomposable if there do not exist permutation matrices, $P$ and $Q$, such that $P A Q=$ $A_{1} \oplus A_{2}$ for some matrices, $A_{1}$ and $A_{2}$.

LEMma 2. Let $A$ be a binary matrix with ones on the diagonal. The following are equivalent:

(i) $A$ is indecomposable

(ii) $A$ is fully indecomposable

(iii) $G(A)$ is weakly connected.

Proof. This is a simple consequence of a result of Brualdi, Parter, and Schneider [2; Lemma 2.3].

3. Constructions. The counterexamples we require can be generated through the proper use of the following three constructions. In each construction the matrices $A_{i} \in U\left(n_{i} ; 3\right)$ satisfy $\operatorname{per} A=|\operatorname{det} A|$ and have only ones on the diagonal. This later condition is not overly restrictive as any matrix in $U(n ; 3)$ can have its rows or columns permuted to put it in this form.

It can easily be verified that in each construction the resulting digraph has only odd cycles, and thus the corresponding matrix has equal permanent and determinant. Furthermore, if the matrices $A_{i}$ are fully indecomposable, then so is the resulting matrix, as the corresponding digraph is strongly connected.

Construction I. Let $A_{1}, A_{2}, \cdots, A_{2 m+1}$ be given for some fixed positive integer $m$. For each $i(i=1,2, \cdots, 2 m+1)$ select from $D\left(A_{i}\right)$ an edge $e_{i}$ from $u_{i}$ to $v_{i}$. Form a new digraph $G$ from $G_{1} \cup G_{2} \cup \cdots \cup$ $G_{2 m+1}$ by deleting the edges $e_{i}(i=1,2, \cdots, 2 m+1)$ and adding edges from $u_{i}$ to $v_{i+1}(i=1,2, \cdots, 2 m)$ and from $u_{2 m+1}$ to $v_{1}$. Clearly $A(G) \in$ $U\left(n_{1}+n_{2}+\cdots+n_{2 m+1} ; 3\right)$ and per $A(G)=\operatorname{det} A(G)$.

Construction II. Let $A_{1}, A_{2}, A_{3}$, and $A_{4}$ be given. For each $i$ $(i=1,2,3,4)$ select from $D\left(A_{i}\right)$ an edge $e_{i}$ from $u_{i}$ to $v_{i}$. Let $v_{0}$ be an additional point. Form a new digraph $G$ from $G_{1} \cup G_{2} \cup G_{3} \cup G_{4} \cup$ $\left\{v_{0}\right\}$ by deleting the edges $e_{i}$ for $i=1,2,3,4$ and adding new edges from $u_{1}$ to $v_{2}$, from $u_{3}$ to $v_{4}$, from $v_{0}$ to $v_{1}$ and $v_{3}$, and from $u_{2}$ and $u_{4}$ to $v_{0}$, and a loop at $v_{0}$. Clearly $A(G) \in U\left(n_{1}+n_{2}+n_{3}+n_{4}+1 ; 3\right)$ and per $A(G)=\operatorname{det} A(G)$.

Construction III. Let $A_{1}, A_{2}, \cdots, A_{4 m+2}$ be given for some fixed 
positive integer $m$. For each $i(i=1,2, \cdots, 4 m+2)$ select from $D\left(A_{i}\right)$ an edge $e_{i}$ from $u_{i}$ to $v_{i}$ and form a new digraph $G_{i}$ by deleting $e_{i}$ and adding two new points $u_{i}^{\prime}$ and $v_{i}^{\prime}$ together with new edges from $u_{i}$ to $u_{i}^{\prime}$, from $u_{i}^{\prime}$ to $v_{i}^{\prime}$, and from $v_{i}^{\prime}$ to $v_{i}$. Form the digraph $G$ from $G_{1} \cup G_{2} \cup \cdots \cup G_{4 m+2}$ by identifying the point pairs $u_{2 i-1}^{\prime}$ and $u_{2 i}^{\prime}$ for $i=1,2, \cdots, 2 m+1, v_{2 i}^{\prime}$ and $v_{2 i+1}^{\prime}$ for $i=1,2, \cdots, 2 m$, and $v_{4 m+1}^{\prime}$ and $v_{1}^{\prime}$, and adding a loop at each of the resulting points. Clearly $A(G) \in U\left(n_{1}+n_{2}+\cdots+n_{4 m+2}+4 m+2 ; 3\right)$ and $\operatorname{per} A(G)=\operatorname{det} A(G)$.

4. Conclusions. We are now ready to prove that Conjecture I is false.

THEOREM 1. Conjecture I is false for $k=3$. In fact for every sufficiently large $n$ there is a fully indecomposable matrix $A \in U(n ; 3)$ satisfying $\operatorname{per} A=\operatorname{det} A$.

Proof. Starting with the matrix $C$, Constructions I, II, and III may be used to generate a family of fully indecomposable matrices with equal permanent and determinant. It can easily be verified that the family contains matrices of order $n$ for all sufficiently large $n$.

The question of the existence of matrices in $U(n ; k)$ for $k \geqq 4$ with equal permanent and determinant remains open. It should be noted, however, that should one such matrix exist for a given $k$, then Constructions I, II, and III with the obvious modifications, may be used to construct an infinite family of such matrices. The problem of finding a good characterization of the matrices in $U(n ; 3)$ with equal permanent and determinant also remains to be solved.

As to Conjecture II, while Datta [4] has shown that Conjecture II is true for even $n$ if $A$ is symmetric and imprimitive; Hartfiel [9] has produced counterexamples for $n=4$ and 5; and Csima [3] has produced an infinite family of counterexamples. Counterexamples for all sufficiently large even $n$ follow directly from the results of Theorem 1. However, more can be said as follows:

THEOREM 2. For each $n \geqq 3$ there is an $n \times n$ indecomposable doubly-stochastic matrix $A_{n}$ such that $f(z)=\operatorname{per}\left(z I-A_{n}\right)$ has $n-2$ distinct real roots in $(0,1)$.

Proof. Start with $A_{3}=J_{3}$, which is clearly satisfactory, and continue inductively.

Suppose $A_{n-1}$ satisfies the conditions of the theorem. The required matrix, $A_{n}$, is constructed as follows. Let $A_{n}(\lambda)=\lambda_{J_{n}}+(1-\lambda)((1) \oplus$ $\left.A_{n-1}\right)$, where $J_{n}$ is the $n \times n$ matrix each of whose entries is $1 / n$. Clearly $A_{n}(\lambda)$ is doubly-stochastic for $0 \leqq \lambda \leqq 1$ and indecomposable 
for $\lambda \neq 0$. Let $B_{n}(\lambda, z)=z I-A_{n}(\lambda)$, and let $g_{n}(\lambda, z)=\operatorname{per} B_{n}(\lambda, z)$. Then

$$
\frac{\partial g_{n}(\lambda, z)}{\partial \lambda}=\sum_{i, j}-\frac{d\left(A_{n}(\lambda)\right)_{i j}}{d \lambda} \operatorname{per}\left(B_{n}(\lambda, z)\right)(i \mid j)
$$

where $\left(A_{n}(\lambda)\right)_{i j}$ is the entry of $A_{n}(\lambda)$ in row $i$ and column $j$, and $\left(B_{n}(\lambda, z)\right)(i \mid j)$ is the matrix obtained from $B_{n}(\lambda, z)$ by deleting row $i$ and column $j$. Observe that $B_{n}(0,1)=(0) \oplus\left(I-A_{n-1}\right)$; hence for $\lambda=0$, $z=1$ all of the terms in the summation above, except the term for $i=j=1$, vanish. Thus

$$
\frac{\partial g_{n}(0,1)}{\partial \lambda}=\left(1-\frac{1}{n}\right) \operatorname{per}\left(I-A_{n-1}\right) \neq 0 .
$$

It follows that for $\lambda>0$ sufficiently small per $\left(I-A_{n}(\lambda)\right) \neq 0$, so that for such $\lambda, z=1$ is not a root of per $\left(z I-A_{n}(\lambda)\right)$. As the roots of per $\left(z I-A_{n}(\lambda)\right)$ are continuous, and, as shown by Brenner and Brualdi [1], the real roots lie on $(0,1]$, it must be the case that for some $\lambda_{0}>0$ per $\left(z I-A_{n}\left(\lambda_{0}\right)\right)$ has $n-2$ real roots in $(0,1)$. Thus the matrix $A_{n}=A_{n}\left(\lambda_{0}\right)$ is as required, and the theorem is proved. We believe that this result may be best possible in the sense that no doubly-stochastic matrix other than the identity yields only real roots.

\section{REFERENCES}

1. J. L. Brenner and R. A. Brualdi, Properties of the permanent function, Notices Amer. Math. Soc., 14 (1967), 87.

2. R. A. Brualdi, S. V. Parter, and H. Schneider, The diagonal equivalence of a nonnegative matrix to a stochastic matrix, J. Math. Anal. Appl., 16 (1966), 31-50.

3. J. Csima, A class of counterexamples on permanents, Pacific J. Math., 37 (1971), 655-656.

4. B. N. Datta, On a conjecture of de Oliveira, Notices Amer. Math. Soc., 17 (1970), 1068.

5. Q. N. de Oliveira, A conjecture and some problems on permanents, Pacific J. Math., 32 (1970), 495-499.

6. F. Harary, The determinant of the adjacency matrix of a graph, SIAM Review, 4 (1962), 202-209.

7. — Graphs and matrices, SIAM Review, 9 (1967), 83-90.

8. — Graph Theory, Addison-Wesley, Reading, Mass., 1969.

9. D. J. Hartfiel, Counterexamples to a conjecture of G. N. de Oliveira, Pacific J. Math., 38 (1971), 67-68.

10. H. Ryser, Matrices of zeros and ones, Bull. Amer. Math. Soc., 66 (1960), 442-463, 11. M. Tinsley, Permanents of cyclic matrices, Pacific J. Math., 10 (1960), 1067-1082.

Received October 18, 1971 and in revised form January 19, 1972.

FLORIDA AtLantic UNIVERSity 


\section{PACIFIC JOURNAL OF MATHEMATICS}

\section{EDITORS}

\section{H. SAMELSON}

Stanford University

Stanford, California 94305

C. R. Новву

University of Washington Seattle, Washington 98105

\section{J. DuGundJI}

Department of Mathematics University of Southern California Los Angeles, California 90007

RICHARD ARENS

University of California Los Angeles, California 90024

\section{ASSOCIATE EDITORS}
E. F. BECKENBACH
B. H. NeumanN
F. WOLF
K. YoSHIDA

\section{SUPPORTING INSTITUTIONS}

\author{
UNIVERSITY OF BRITISH COLUMBIA \\ CALIFORNIA INSTITUTE OF TECHNOLOGY \\ UNIVERSITY OF CALIFORNIA \\ MONTANA STATE UNIVERSITY \\ UNIVERSITY OF NEVADA \\ NEW MEXICO STATE UNIVERSITY \\ OREGON STATE UNIVERSITY \\ UNIVERSITY OF OREGON \\ OSAKA UNIVERSITY
}

\author{
UNIVERSITY OF SOUTHERN CALIFORNIA \\ STANFORD UNIVERSITY \\ UNIVERSITY OF TOKYO \\ UNIVERSITY OF UTAH \\ WASHINGTON STATE UNIVERSITY \\ UNIVERSITY OF WASHINGTON \\ $*{ }^{*}$
AMERICAN MATHEMATICAL SOCIETY
NAVAL WEAPONS CENTER
}

The Supporting Institutions listed above contribute to the cost of publication of this Journal, but they are not owners or publishers and have no responsibility for its content or policies.

Mathematical papers intended for publication in the Pacific Journal of Mathematics should be in typed form or offset-reproduced, (not dittoed), double spaced with large margins. Underline Greek letters in red, German in green, and script in blue. The first paragraph or two must be capable of being used separately as a synopsis of the entire paper. The editorial "we" must not be used in the synopsis, and items of the bibliography should not be cited there unless absolutely necessary, in which case they must be identified by author and Journal, rather than by item number. Manuscripts, in duplicate if possible, may be sent to any one of the four editors. Please classify according to the scheme of Math. Rev. Index to Vol, 39. All other communications to the editors should be addressed to the managing editor, Richard Arens, University of California, Los Angeles, California, 90024.

50 reprints are provided free for each article; additional copies may be obtained at cost in multiples of 50 .

The Pacific Journal of Mathematics is issued monthly as of January 1966. Regular subscription rate: $\$ 48.00$ a year (6 Vols., 12 issues). Special rate: $\$ 24.00$ a year to individual members of supporting institutions.

Subscriptions, orders for back numbers, and changes of address should be sent to Pacific Journal of Mathematics, 103 Highland Boulevard, Berkeley, California, 94708.

PUBLISHED BY PACIFIC JOURNAL OF MATHEMATICS, A NON-PROFIT CORPORATION

Printed at Kokusai Bunken Insatsusha (International Academic Printing Co., Ltd.), 270, 3-chome Totsuka-cho, Shinjuku-ku, Tokyo 160, Japan. 


\section{Pacific Journal of Mathematics}

\section{Vol. 44, No. $2 \quad$ June, 1973}

Tsuyoshi Andô, Closed range theorems for convex sets and linear liftings . . . . . . 393

Richard David Bourgin, Conically bounded sets in Banach spaces . . . . . . . . . 411

Robert Jay Buck, Hausdorff dimensions for compact sets in $R^{n} \ldots \ldots \ldots \ldots \ldots \ldots . \ldots 421$

Henry Cheng, A constructive Riemann mapping theorem ................ 435

David Fleming Dawson, Summability of subsequences and stretchings of

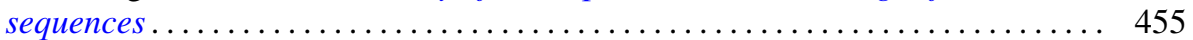

William Thomas Eaton, A two sided approximation theorem for 2-spheres ....... 461

Jay Paul Fillmore and John Herman Scheuneman, Fundamental groups of compact complete locally affine complex surfaces ....................... 487

Avner Friedman, Bounded entire solutions of elliptic equations . . . . . . . . . . . 497

Ronald Francis Gariepy, Multiplicity and the area of an $(n-1)$ continuous

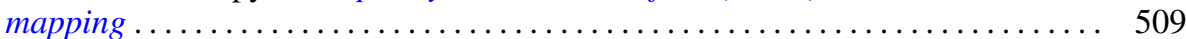

Andrew M. W. Glass, Archimedean extensions of directed interpolation groups . . . . 515

Morisuke Hasumi, Extreme points and unicity of extremum problems in $H^{1}$ on

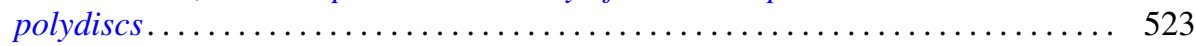

Trevor Ongley Hawkes, On the Fitting length of a soluble linear group . . . . . . 537

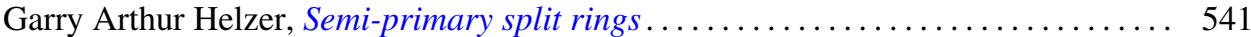

Melvin Hochster, Expanded radical ideals and semiregular ideals . . . . . . . . . 553

Keizō Kikuchi, Starlike and convex mappings in several complex variables . . . . . . 569

Charles Philip Lanski, On the relationship of a ring and the subring generated by its

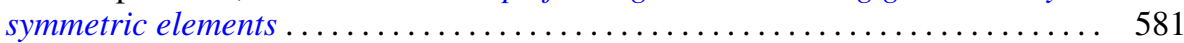

Jimmie Don Lawson, Intrinsic topologies in topological lattices and semilattices ........................................... 593

Roy Bruce Levow, Counterexamples to conjectures of Ryser and de Oliveira ...... 603

Arthur Larry Lieberman, Some representations of the automorphism group of an infinite continuous homogeneous measure algebra ..........

William George McArthur, $G_{\delta}$-diagonals and metrization theorems $\ldots .$.

James Murdoch McPherson, Wild arcs in three-space. II. An invariant of

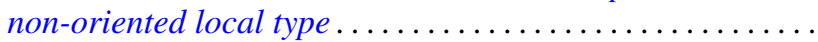

H. Millington and Maurice Sion, Inverse systems of group-valued measures ...

C. Edward Moore, Concrete semispaces and lexicographic separation of convex

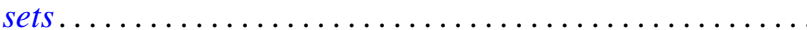

Jingyal Pak, Actions of torus $T^{n}$ on $(n+1)$-manifolds $M^{n+1}$.

Merrell Lee Patrick, Extensions of inequalities of the Laguerre and Turán type . . . . 675

Harold L. Peterson, Jr., Discontinuous characters and subgroups of finite index. . . . 683

S. P. Philipp, Abel summability of conjugate integrals . . . . . . . . . . . . . 693

R. B. Quintana and Charles R. B. Wright, On groups of exponent four satisfying an

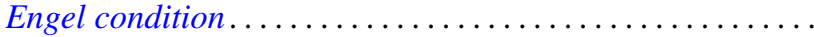

Marlon C. Rayburn, On Hausdorff compactifications. . . . . . . . . .

Martin G. Ribe, Necessary convexity conditions for the Hahn-Banach theorem in

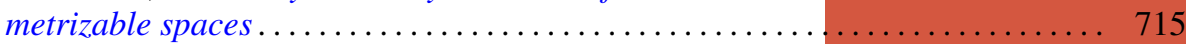

Ryōtarō Satō, On decomposition of transformations in infinite measure spaces .... 733

Peter Drummond Taylor, Subgradients of a convex function obtained from a

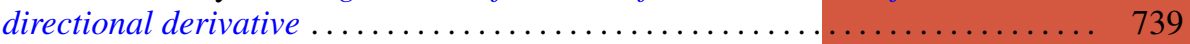

James William Thomas, A bifurcation theorem for $k$-set contractions . . . . . . . . 749 Clifford Edward Weil, A topological lemma and applications to real functions . . . . 757

Stephen Andrew Williams, A nonlinear elliptic boundary value problem . . ....... 767

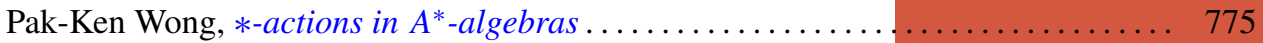

